Ulrike Fasbender, Jurgen Deller, Mo Wang, Brenton M Wiernik

Deciding whether to work after retirement: the role of the psychological experience of aging Journal of Vocational Behavior, vol. 84, no. 3 (2014)

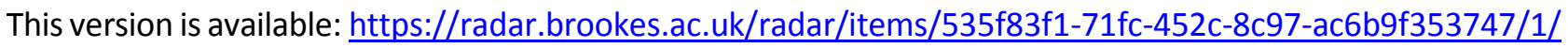

Available on RADAR: 17.02 .2017

Copyright ( $)$ and Moral Rights are retained by the author(s) and/ or other copyright owners. A copy can be downloaded for personal non-commercial research or study, without prior permission or charge. This item cannot be reproduced or quoted extensively from without first obtaining permission in writing from the copyright holder(s). The content must not be changed in any way or sold commercially in any format or medium without the formal permission of the copyright holders.

This document is the authors' accepted version. 
Deciding whether to work after retirement: The role of the psychological experience of aging

Ulrike Fasbender and Jürgen Deller

Leuphana University of Lüneburg, Germany

Mo Wang

University of Florida

Brenton M. Wiernik

University of Minnesota

Author Note

Ulrike Fasbender, Leuphana University of Lüneburg, Institute of Strategic HR Management Research and Development (SMARD); Jürgen Deller, Leuphana University of Lüneburg, Institute of Strategic HR Management Research and Development (SMARD); Mo Wang, Department of Management, Warrington College of Business Administration, University of Florida; Brenton M. Wiernik, Department of Psychology, University of Minnesota.

The data used in this study are provided by the Research Data Centre of the German Centre of Gerontology (DZA).

Correspondence concerning this article should be addressed to Ulrike Fasbender, Leuphana University of Lüneburg, Institute of Strategic HR Management Research and Development (SMARD); Wilschenbrucher Weg 84, 21335 Lüneburg, Germany, Phone: +49 176 96602125, E-mail: fasbender@leuphana.de 


\begin{abstract}
Due to the graying of the global labor markets, post-retirement employment is becoming increasingly important in the $21^{\text {st }}$ century. To better understand older people's decisions to engage in post-retirement employment, the current study investigated the role of the psychological experience of aging. Two dimensions that capture positive aging experience (i.e., personal growth and gaining self-knowledge) and two dimensions that capture negative aging experience (i.e., physical loss and social loss) were differentiated and their relations to post-retirement employment were hypothesized. We argue that aging experience may influence the decision to work after retirement by generating both, approach and avoidance responses. Longitudinal data from the German Aging Survey $(N=551)$ were used to test the hypotheses. The results of structural equation modeling indicated that retirees who experienced aging as social loss and as personal growth were more likely to engage in postretirement employment a decade later, while retirees who experienced aging as gaining selfknowledge were less likely to engage in post-retirement employment. Theoretical and practical implications of this study are discussed.
\end{abstract}

Keywords: aging workforce, bridge employment, post-retirement employment, psychological aging experience, retirement 


\section{Deciding whether to work after retirement: \\ The role of the psychological experience of aging}

Life expectancy has increased consistently for more than one century and continues to increase further (Organization for Economic Co-operation and Development [OECD], 2011). This has resulted in important shifts in the aging process because the years of healthy life (i.e., free from morbidity and disability) have also increased (Christensen, Doblhammer, Rau, \& Vaupel, 2009). People remain fit and healthy longer than ever before. As a result, retirement from ordinary work life is no longer the time to withdraw from society, but rather a time when people now remain active.

A key way that individuals remain active as they age is to continue employment. The rate of older people working in Germany has doubled over the last 10 years (e.g., labor force participation rate changed from 2001 to 2011 for people aged $60-64: 23.3 \%$ to $47.3 \%$; $65-69$ : 5.4\% to $10.2 \%$; $70-74: 2.7 \%$ to $4.7 \%$; $75+: 0.9 \%$ to $1.4 \%$; OECD, 2013$)$. Prolonged health and longevity have improved the aging process and post-retirement employment has become a meaningful option for older people to use their time after ending their main employment. Post-retirement employment refers to paid work beyond mandatory or median retirement age as well as pension receiving state, including part-time jobs and self-employment (Shultz, 2003). It is part of an ongoing process of psychological detachment from work in which people experience a transition from labor force participation to complete retirement (Shultz, 2003; Wang, Adams, Beehr, \& Shultz, 2009). Recently, the concept of retirement has been refined as a late career development stage, in which work activities may continue to play a central role (Kim \& Hall, 2013; Shultz \& Wang, 2011; Wang \& Shi, 2014). While many people still decide to directly withdraw from employment when leaving their career jobs, a growing number of individuals are taking part in work beyond retirement (Cahill, Giandrea, \& Quinn, 2007; Deller \& Pundt, in press; Eurofound, 2012; Wang et al., 2009). 
Post-retirement employment is of interest to individuals, organizations and society as a whole (Griffin \& Hesketh, 2008). From the societal perspective, post-retirement employment offers a potential solution to pressing population concerns. Increased longevity and low birth rates are contributing to widespread demographic shifts which are likely to create imbalances between the decreasing working and the increasing retired populations (Beehr, Glazer, Nielson, \& Farmer, 2000; Dalen, Henkens, Henderikse, \& Schippers, 2010; Wang \& Shi, 2014). Such imbalances impact the financial feasibility of social pension funds. As a result, many industrialized nations are increasingly interested in individuals continuing to work beyond retirement age in order to reduce retirees' dependency on social pension funds (Deller, Liedtke, \& Maxin, 2009; Müller, De Lange, Weigl, Oxfart, \& Van der Heijden, 2013).

From the organizational perspective, the shrinking size of the labor force will result in vital skills shortages, leading organizations to be interested in post-retirement employment as a means to retain the skills and knowledge of experienced older workers (Mariappanadar, 2013; Shultz \& Wang, 2011). This retention of human capital, combined with the reduced burden on social pension funds, suggests that increased frequency of post-retirement employment will result in enormous economic benefits (Griffin \& Hesketh, 2008).

From the individual perspective, post-retirement employment appears to contribute to greater psychological well-being and life-satisfaction (e.g., Kim \& Feldman, 2000; Wang, 2007; Warr, Butcher, Robertson, \& Callinan, 2004). Similarly, longitudinal research by Zhan, Wang, Liu, and Shultz (2009) demonstrated improved physical and mental health outcomes for employed retirees. Post-retirement employment may also be beneficial by providing a structured daily routine, supplemental income, and support during the transition and adjustment to retirement (Herzog, House, \& Morgan, 1991; Wang, 2007). 
While the potential individual, organizational and societal benefits of post-retirement employment are apparent, little is known about what factors lead individuals to pursue work after retiring (Griffin \& Hesketh, 2008), especially the psychological factors, such as the aging experience (Dittmann-Kohli et al., 1997). Because post-retirement employment means to work when one is old, it is most obvious that the age itself is an important factor to one's decision to work or not to work post retirement. Besides, with increasing age people experience positive and negative changes. New experiences are compared to the past, while prior experiences help to interpret upcoming events and to make decisions in the future, which influences individual's behaviors and actions (Bandura, 1986). The manner in which individuals experience the process of aging — their psychological aging experience — can influence their decisions about the future, including their choice to work after retirement. Although previous research has theorized that aging-related cognitions can shape people's behaviors and outcomes (e.g., Lerner \& Busch-Rossnagel, 1981; Markus \& Herzog, 1992; Steverink, Westerhof, Bode, \& Dittmann-Kohli, 2001; Wurm, Tesch-Römer, \& Tomasik, 2007), there is no empirical research about how the aging experience shapes individuals' decisions about post-retirement employment. The few studies that have taken aging experience into account have concentrated on either health (Wurm et al., 2007) or on subjective well-being (Steverink et al., 2001).

For this reason, the purpose of the present study is to investigate the decision to work after retirement and the role of the psychological experience of aging. In doing so, we emphasize two aims. First, we aim to investigate the psychological aging experience as a multidimensional construct, taking both positive and negative aging experiences into account. Previous research has mainly focused on positive aging experience that fosters positive outcomes and negative aging experience that fosters negative outcomes (e.g., Steverink et al., 2001; Wurm et al., 2007). In this study, we propose two mechanisms that describe when 
positive and negative aging experiences foster post-retirement employment and when they hinder post-retirement employment, depending on the fit between the aging experience dimension and the outcome variable. The second aim is to examine post-retirement employment as an actual behavior. Heretofore, empirical studies have focused on individuals' intentions to work post-retirement (e.g., Lim \& Feldman, 2003; Mariappanadar, 2013; Weckerle \& Shultz, 1999). Recently, Wöhrmann, Deller, and Wang (2013) have identified a decrease in physical demands and an increase in social support at work as key determinants of older worker's intention to work post-retirement. However, these studies were limited by examining post-retirement employment intentions rather than the actual behavior to work after retirement. In sum, to address the above-mentioned research gaps, the present study examines the relationship between different dimensions of the psychological aging experience and actual post-retirement employment using longitudinal data from the population-representative German Aging Survey.

\section{Theoretical Background}

\section{Psychological Aging Experience}

Psychological aging experience (or simply aging experience) is a multidimensional construct that refers to an individual's different cognitions regarding his or her own ongoing aging process (Dittmann-Kohli et al., 1997). This aging process can be positively or negatively experienced (Atchley, 1982), and it can be experienced differently in various domains (Steverink et al., 2001). Further, aging experience is an important part of the selfconcept, which develops over the whole life span taking internal and external information into account (De Gracia Blanco et al., 2004; Markus \& Herzog, 1992). Specifically, older people see themselves now and they have seen themselves when they were young. Both views lead to an internal comparison of how life has changed during this aging process. These changes are often experienced as either gains or losses (Markus \& Herzog, 1992). 
On the basis of both qualitative and quantitative research (e.g., Connidis, 1989; Dittmann-Kohli, 1995; Heckhausen, Dixon, \& Baltes, 1989; Keller, Leventhal, \& Larson, 1989), Dittmann-Kohli et al. (1997) established a taxonomy of psychological aging experience, which includes four dimensions: physical loss, social loss, personal growth, and gaining self-knowledge. Physical loss and social loss are two dimensions that capture negative aging experience. The dimension of physical loss describes the aging process as a decline of physical abilities and the loss of energy. The dimension of social loss describes the aging process as a loss of social contacts and a feeling of being less needed and less respected. Personal growth and gaining self-knowledge are two dimensions that capture positive aging experience. The dimension of personal growth describes the aging process as continuous personal development, including such experiences as learning new skills and improving one's capabilities. The dimension of gaining self-knowledge describes the aging process as self-acceptance and compensation (i.e. understanding one's capabilities and developing methods to work around one's limitations). Individuals experience aging as a combination of these four dimensions; people's aging processes can be differentiated by their standing on each of these dimensions.

\section{Aging Experience and Post-retirement Employment Decision}

Because the aging experience is an evaluation of the ongoing aging process, it contains a prognostic component, which influences an individual's potential to take action at their current phase of life (Dittmann-Kohli, et al., 1997). Therefore, the aging experience is likely to influence an individual's actual decision to work post-retirement. Previous research has shown that positive aging experience is likely to foster positive outcomes and negative aging experience is likely to foster negative outcomes (Steverink et al., 2001; Wurm et al., 2007). However, this pattern cannot hold for post-retirement employment because it is neither a positive nor a negative outcome by nature. Therefore, both positive and negative aging 
experience are likely to influence the decision by changing individuals' expectations of postretirement employment helping or hindering their individual needs.

However, it is important to note that this influence is not simply determined by the valence of aging experience (i.e. positive aging experience does not necessarily lead individuals to pursue post-retirement employment and negative aging experience lead them to avoid it), but more related to the fit between the behavior of interest and the specific domain of aging experience. Therefore, we argue that aging experience may influence the decision to work after retirement via both an approach mechanism and an avoidance mechanism. The approach-avoidance distinction in psychological processes has been shown to be fundamental in explaining human affect, cognition, and behaviors (Elliot \& Thrash, 2002). In particular, they can serve as basic behavioral orientations in decision making situations. Avoidance is a functional reaction to expected undesirable outcomes, while approach is a functional reaction to expected desirable outcomes.

Specifically, on the one hand, the approach mechanism can manifest when postretirement employment is beneficial for a person to achieve certain positive aging experience. The approach mechanism can also manifest when post-retirement employment is beneficial in relieving one's certain negative aging experience. In both of these situations, positive aging experience and negative aging experience in the specific domains would be positively related to post-retirement employment decisions (i.e., approaching post-retirement employment). On the other hand, the avoidance mechanism can manifest when postretirement employment is expected to block one from achieving certain positive aging experience. The avoidance mechanism can also manifest when post-retirement employment is expected to lead to negative aging experience. In both of these situations, positive aging experience and negative aging experience in the specific domains would be negatively related to post-retirement employment decisions (i.e., avoiding post-retirement employment). In the 
following we apply the two mechanisms to the four specific aging experience dimensions to develop our hypotheses.

\section{The Current Study}

The current study aims to investigate the relationship between four dimensions of aging experience and post-retirement employment. We consider how each form of aging experience may affect expectations regarding the outcomes of employment and influence individuals' decisions to work post-retirement.

First, aging can be experienced as physical loss. This experience is related to perceptions of declines in an individual's physical abilities, loss of energy and fitness, and problems coping with physical demands (Steverink et al., 2001). Physical loss is associated with poor health, high negative affectivity, and low positive affectivity (Steverink et al., 2001; Wurm et al., 2007). Individuals who experience aging as physical loss are likely to be concerned about physical exertion and to avoid taxing activities. Employment is often perceived as physically and cognitively tiring. When retirees experience aging as physical loss, they might interpret employment as an additional burden to their health. As such, experiencing physical loss may lead retirees to avoid post-retirement employment. Therefore, we hypothesize that retirees who experience aging more as physical loss will be less likely to engage in post-retirement employment.

Hypothesis 1: Physical loss will be negatively related to post-retirement employment.

Second, aging can be experienced as social loss. This experience refers to the perception of the loss of social contacts, loneliness, and feelings of being less needed and less respected (Steverink et al., 2001). Continued employment by older individuals is associated with increased social support by supervisors, colleagues, or even customers (Aquino, Russell, Cutrona, \& Altmaier, 1996). Similarly, when individuals are part of socially supportive workplaces, they are more likely to intend to engage in same-employer-post-retirement 
employment (Wöhrmann et al., 2013). When retirees experience aging as social loss, they may see employment as a way to fulfill their needs for social contact and support, leading them to approach post-retirement employment. Therefore, we hypothesize that retirees who experience aging more as social loss will be more likely to engage in post-retirement employment.

Hypothesis 2: Social loss will be positively related to post-retirement employment.

Third, aging can be experienced as personal growth. This experience refers to continued personal development, expansion of personal capabilities, and increased feelings of self-worth (Steverink et al., 2001). Personal growth is a future-oriented way of experiencing aging (Wurm et al., 2007). Retirees who experience aging as personal growth are likely to be confident in pursuing opportunities for development and improved productivity. To these individuals, employment may represent an important opportunity to pursue productive selfimage and expand professional knowledge and skills. Therefore, with regard to this domain of aging experience, post-retirement employment is likely to be interpreted as beneficial and experiencing personal growth may lead retirees to approach post-retirement employment. Consequently, we hypothesize that retirees who experience aging more as personal growth will be more likely to engage in post-retirement employment.

\section{Hypothesis 3: Personal growth will be positively related to post-retirement employment.}

Finally, aging can be experienced as gaining self-knowledge. This experience refers to self-acceptance and feelings that one can embrace one's limitations (Steverink et al., 2001). When retirees experience aging as gaining self-knowledge, they are very much aware of their current abilities, but also of their disabilities. As individuals view themselves over the complete life span, the experience of gaining self-knowledge is likely to convert into the acceptance of not being as capable as they used to be (Wurm et al. 2007). As individuals 
accept their growing limitations, they may avoid taking on production-related responsibilities. As a result, these individuals may prefer to pursue other activities that are different from working (working may also prevent them from new opportunities to continue to gain selfknowledge) and that are within the scope of their present capabilities, leading them to avoid post-retirement employment. Therefore, we hypothesize that retirees who experience aging as gaining self-knowledge will be less likely to engage in post-retirement employment.

Hypothesis 4: Gaining self-knowledge will be negatively related to post-retirement employment.

\section{Method}

\section{Participants and Procedure}

For our analyses, we used longitudinal data from the German Aging Survey, a population-representative survey of middle-aged and older adults in Germany (Engstler \& Motel-Klingebiel, 2010). The survey is an ongoing study that, to this point, was organized over a 12-year period. We analyzed data from the 1996 and 2008 waves. The survey consists of two parts. Face-to-face interviews were conducted at respondents' homes by trained interviewers according to a standardized questionnaire. Drop-off questionnaires were conducted using paper and pencil in 1996 and computers in 2008. For the baseline sample in 1996, stratified sampling by age, gender, and geographical location (Eastern or Western Germany) was used. Of all contacted individuals, $45.6 \%(N=4,838)$ agreed to participate in the interview. The response rate is comparable to that of other population surveys in Germany (Neller, 2005). Of those interviewed, 83.4\% $(N=4,034)$ also completed the dropoff questionnaire. Participants were asked to take part in future research and $61.4 \%(N=$ 2,972) agreed to do so. During the process, drop out occurred due to refused participation, incompletion of either the interview or the drop-off questionnaire, movement to unknown addresses, or death. In 2008, the longitudinal sample consisted of $N=994$ participants. 
Given the research question of our study, we only included pensioners in our study. In other words, retirement status was determined by whether individuals were receiving a pension (Shultz \& Wang, 2011). In Germany, the regular pension age is 65 (for people born before 1949). However, a reduced pension can be received as early as 60 (for people born before 1952; German Statutory Pension Insurance Scheme, 2013). Therefore, we set 60 as the minimum age in our sample. We set a maximum age of 85 because we assume that the workability of people above this age is strongly limited in most cases. The final sample size including pensioners from 60 to 85 (in 2008) was $N=551$.

On average, participants were 71.92 years old $(S D=6.30)$ in 2008. The sample consisted of $56.1 \%$ male participants $(n=309)$. Regarding education level, $10.0 \%$ of the participants had only primary or middle school education without further vocational training $(n=55), 55.6 \%$ of the participants had a medium level of education, including secondary school or vocational training $(n=305)$, and $34.4 \%$ of the participants had a high level of education, including advanced vocational training or a university degree $(n=189)$. In 2008 , participants evaluated their health and their economic status on a 5 -point scale $(1=$ very good to $5=$ very $b a d)$. In the current study, values were recoded so that the higher values of the scale indicate greater health or greater economic status. About half $(49.7 \%)$ of the participants evaluated their health as either good $(n=243)$ or very good $(n=30), 38.2 \%$ evaluated their health as medium $(n=210)$, and $12.1 \%$ of the participants evaluated their health as bad $(n=58)$ or very bad $(n=9)$. Majority of the participants $(69.2 \%)$ evaluated their economic status as good $(n=323)$ or very good $(n=56), 27.4 \%$ evaluated their economic status as medium $(n=150)$ and only $3.3 \%$ of the participants evaluated their economic status as bad $(n=16)$ or very bad $(n=2)$.

\section{Measures}


Post-retirement employment. Post-retirement employment was measured with one item in 2008: "Sometimes pensioners and retirees keep working after retirement. What about you: Are you working at the moment?" Responses to this question were binary and recoded $(0=$ no post-retirement employment, $1=$ post-retirement employment $)$. Forty-six participants $(8.4 \%)$ reported that they engaged in post-retirement employment.

Aging experience. Aging experience was assessed with the four dimensions of aging experience: physical loss, social loss, personal growth, and gaining self-knowledge using items from Dittmann-Kohli et al. (1997). Each dimension was originally measured with four items on a 4-point scale $(1=$ strongly agree to $4=$ strongly disagree $)$ in 1996. We recoded all items in the current study so that the higher values of the scale indicate greater experience of the dimension. Sample items were: for physical loss, "For me, getting older means that I am less healthy"; for social loss, "Aging means to me that I feel lonely more often"; for personal growth, "Aging means to me that I continue to make plans"; and for gaining self-knowledge, "Aging means to me that I know myself better."

Reliabilities were moderate for each dimension $(\alpha=.76$ for physical loss, $\alpha=.74$ for social loss, $\alpha=.73$ for personal growth, $\alpha=.68$ for gaining self-knowledge). To ensure the construct validity of the four psychological aging experience dimensions, we conducted a confirmatory factor analysis. The results clearly support the four-factor model $\left(\chi^{2}[98]=\right.$ $245.51, p<.01, \mathrm{CFI}=.92, \mathrm{RMSEA}=.06, \mathrm{SRMR}=.05)$ over the one-factor solution $\left(\chi^{2}[104]\right.$ $=1,127.74, p<.01, \mathrm{CFI}=.46, \mathrm{RMSEA}=.14, \mathrm{SRMR}=.12)$ or the two-factor solution with physical loss and social loss items loading on the same factor that captures negative aging experience and personal growth and gaining self-knowledge items loading on the same factor that captures positive aging experience $\left(\chi^{2}[103]=755.63, p<.01, \mathrm{CFI}=.66, \mathrm{RMSEA}=.11\right.$, $\operatorname{SRMR}=.10)$ 
Control variables. Age, gender, level of education, subjective health, and subjective economic status were used as control variables in the current study, as previous research has shown that these are relevant predictors for post-retirement employment (e.g., Davis, 2003; Griffin \& Hesketh, 2008; Wang, Zhan, Liu, \& Shultz, 2008). Those control variables were all measured in 2008. Additionally, we controlled for people's previous employment status. In $1996,47.0 \%$ of the participants $(n=259)$ engaged in either post- or pre-retirement employment.

\section{Results}

\section{Preliminary Analysis}

Means, standard deviations and correlations of all variables in this study are shown in Table 1. Post-retirement employment was significantly and positively correlated with subjective health $(r=.15, p<.01)$, subjective economic status $(r=.07, p<.05)$, previous employment status $(r=.24, p<.01)$, and personal growth $(r=.08, p<.05)$. It was also significantly and negatively correlated with age $(r=-.19, p<.01)$, and physical loss $(r=-.12$, $p<.01)$. Given the low base rate of post-retirement employment, these relationships can be regarded as quite substantial. Correlations with post-retirement employment were weaker (and not statistically significant) for gender, level of education, gaining self-knowledge or social loss.

Please insert Table 1 about here.

\section{Hypothesis Testing}

Structural equation modeling (SEM) was used to predict post-retirement employment with physical loss, social loss, personal growth and gaining self-knowledge as latent dimensions of aging experience using Mplus 7.0 (Muthén \& Muthén, 2012). Within the structural part of SEM, we used latent logistic link function because the dependent variable (i.e., post-retirement employment) is categorical. We conducted the analysis in three steps. In 
Model 1 (i.e., the baseline null model), neither control variables nor predictors were specified to have effects on the dependent variable. In Model 2, only control variables' effects were estimated on the dependent variable. In Model 3, effects of four aging experience dimensions were estimated in addition to the control variables. The model comparison results are presented in Table 2 .

Please insert Table 2 about here.

Overall, the hypothesized model (Model 3) showed significantly better fit than Model $1(\Delta-2 \log$ likelihood $=53.76, p<.01, \Delta \mathrm{df}=10)$ and marginally better than Model $2(\Delta-2$ $\log$ likelihood $=8.69, p<.10, \Delta \mathrm{df}=4)$. Further, the overall improvement in pseudo $\mathrm{R}^{2}$ was .09 for post-retirement employment. This is a sizable effect considering that we measured the actual behavior to engage in post-retirement employment. Thus, we conclude that it is meaningful to use psychological aging experience in predicting post-retirement employment.

The estimated structural coefficients of the hypothesized model are presented in Figure 1. With regard to the control variables, the previous employment status was significantly and positively related to post-retirement employment $(B=1.63, p<.01, \mathrm{OR}=$ 5.12). This result indicates that retirees who were previously employed were 5.12 times more likely to engage in post-retirement employment, holding all other predictors constant. Subjective health was marginally and positively related to post-retirement employment $(B=$ $0.48, p<.10, \mathrm{OR}=1.61)$. This result indicates that retirees who have evaluated their health one-unit higher were 1.61 times more likely to engage in post-retirement employment. No significant effects were found for age, gender, level of education, and subjective economic status as control variables.

Please insert Figure 1 about here. 
Hypotheses 1 to 4 addressed the relationship between psychological aging experience and post-retirement employment. The SEM structural coefficients suggested that experience of physical loss $(B=-0.30, p>.10, \mathrm{OR}=0.74)$ did not significantly predict the probability of post-retirement employment, not supporting Hypothesis 1. This null effect was likely due to controlling for subjective health. However, social loss, personal growth and gaining selfknowledge were significant predictors of post-retirement employment. Specifically, social loss was positively related to post-retirement employment $(B=0.59, p<.05, \mathrm{OR}=1.80)$. This result is consistent with Hypothesis 2 and indicates that participants who experienced higher levels of social loss as aging experience in 1996 were 1.80 times more likely to engage in post-retirement employment in 2008. Personal growth was positively related to postretirement employment $(B=0.74, p<.05, \mathrm{OR}=2.10)$. This result is consistent with Hypothesis 3 and indicates that participants who experienced higher levels of personal growth as aging experience in 1996 were 2.10 times more likely to engage in post-retirement employment in 2008. Gaining self-knowledge was negatively related to post-retirement employment $(B=-0.54, p=.05, \mathrm{OR}=0.58)$. This result supports Hypothesis 4 and indicates that participants who experienced higher levels of gaining self-knowledge as aging experience in 1996 were 0.58 times less likely to engage in post-retirement employment in 2008.

\section{Discussion}

In the current paper, we examined four dimensions of aging experience (physical loss, social loss, personal growth, and gaining self-knowledge). Physical loss and social loss were two dimensions that capture negative aging experience; personal growth and gaining selfknowledge were two dimensions that capture positive aging experience. We controlled for age, gender, education, subjective health, subjective economic status, and the previous employment status. Among the control variables, retirees who previously worked and had 
better subjective health were more likely to engage in post-retirement employment. These findings were consistent with previous research (Griffin \& Hesketh, 2008; Kim, \& Feldman, 2000; Wang et al., 2008). We found no significant effects for age, gender, education and subjective economic status, though limited variance for education and economic status may be the cause of these null effects. Further, the age effect was likely eliminated by including the previous employment status to the model simultaneously. Both variables share common variance in explaining post-retirement employment, which reflects the retirement institution in Germany where the pension age is fixed by law.

Regarding the aging experience, retirees who experienced aging as social loss were more likely to engage in post-retirement employment. Although social loss is a dimension that captures negative aging experience, an approach mechanism likely occurred because employment can provide social support among older people (Aquino et al., 1996). Retirees with more experience in this dimension are likely to engage in employment to compensate for their experienced loss of social contacts and feelings of being less needed.

Further, we found that retirees who experienced their own aging process as personal growth were more likely to engage in post-retirement employment. This dimension describes a very positive view towards aging and is therefore likely to enhance positive outcomes (Wurm et al., 2007). Therefore, consistent with the approach mechanism we theorized, retirees with more experience in this dimension are likely to engage in employment to further expand their professional knowledge and skills. For these individuals, post-retirement employment serves as an instrument for further personal development.

We also found that retirees who experienced their aging process as gaining selfknowledge were less likely to engage in post-retirement employment. Although gaining selfknowledge is a dimension that captures positive aging experience, an avoidance mechanism likely occurred because retirees with more aging experience in gaining self-knowledge may 
be more aware of their limitations, leading them to seek out activities where these limitations are not problematic. Additionally, non-work activities may afford more opportunities to continue self-discovery. As such, continuing working after retirement may prevent retirees in this dimension of aging experience from fully realizing the benefits of their aging process, leading them to avoid post-retirement employment.

The current study did not find the hypothesized negative relationship between the experience of physical loss and post-retirement employment. Although the experience of physical loss was significantly and negatively related to post-retirement employment $(r=-$ $.12, p<.01)$, the results of the SEM did not show a significant effect above the included control variables and other predictors in the current study. This null effect is likely due to controlling for subjective health. Although the experience of physical loss refers to more than a decrease in health (i.e., being less energetic and fit), according to their correlation $(r=-.22$, $p<.01$ ), both variables might share common variance in predicting post-retirement employment the incremental effect of other aspects of physical loss may not be strong enough to show a substantial influence on employment decisions. This finding is consistent with Wurm et al.'s (2007) suggestion that there is a reciprocal relationship between the experience of physical loss and health issues.

\section{Theoretical and practical implications}

The results of the current study extend research on post-retirement employment. Although many individual attributes (i.e., demographic characteristics, health and financial circumstances, attitudes toward retirement, knowledge, skills, and abilities) that impact the retirement process have been considered in previous empirical studies (Shultz \& Wang, 2011; Wang \& Shultz, 2010), research has largely overlooked how people's experiences with the ongoing process of aging impact retirement experiences and behaviors. The current study focused on this issue and provides some important theoretical and practical implications. 
Theoretically, the current study clearly distinguished four dimensions of aging experience and showed their different effects on post-retirement employment. Previous research has often relied on using subjective age identification (i.e. "How old do you feel?") as a proxy for such aging experience, limiting researchers' ability to comprehensively assess what it means to grow old for retirees. Our findings suggest that ignoring the multidimensionality of aging experience may overlook the complex impact of the aging process on post-retirement activities, especially when different aging experiences may drive individuals to approach or avoid post-retirement employment.

Our findings further extended previous research that showed positive aging experience fostered positive outcomes and negative aging experience fostered negative outcomes. In particular, we enriched previous theorizing associated with the impact of aging experience by proposing an approach mechanism and an avoidance mechanism depending on the opportunity for employment to meet individuals' needs during their aging process. Supporting this conceptualization, our findings suggest that an approach mechanism manifests when post-retirement employment supports an individual's positive aging experiences or relieve his or her negative aging experiences. In contrast, an avoidance mechanism may manifest when post-retirement employment is expected to prevent one from achieving positive aging experiences or lead to negative aging experiences. Overall, our findings highlight the importance of considering very specifically how retirees experience their own aging process in understanding their behavior to engage in post-retirement employment.

Practically, our findings suggest that organizations that want their skilled workers to engage in post-retirement employment may have various options. First, the benefits of postretirement employment should be promoted according to different aging experiences (e.g., promote the idea of social support at work and opportunities to develop). Second, when 
recruiting from internal human resources, organizations should concentrate on people who personally experience aging as personal growth. Mangers should be educated in appropriate strategies to identify these individuals and encourage them to stay for post-retirement employment, such as by conducting pre-retirement interviews and helping individuals to form retirement plans. Third, organizations should design the work for older workers to enable personal development rather than stagnation and enable social exchange rather than isolation. When doing so, the individual needs and desires of older workers should be considered, as personal development is a unique process that differs from person to person according to their own professional experiences.

The current study also suggests that local communities might benefit by implementing programs for newly (and nearly) retired people, in which exchange of aging experiences is promoted and opportunities to fulfill their individual needs are clarified. Post-retirement employment and its benefits should be promoted as one alternative to meaningfully use the time in retirement. Different possibilities and their concrete prospects to engage in postretirement employment should be discussed (e.g., job platforms, self-employment).

\section{Limitations and Future Research}

The current study had several limitations. Most of these limitations are directly related to the data used. First, the potential for selective drop-out, which is typical for longitudinal studies, may limit the generalizability of the study findings. However, Schöllgen, Huxhold, and Schmiedek (2012) have shown that the selectivity effects in the attrition over time in the German Aging Survey were quite weak.

Second, the post-retirement employment participation rate among the study participants was low $(8.4 \%, n=46)$, which may lead to underestimation of the potential effects. The results of this study should thus be considered lower bound estimates for the influence of the aging experience on post-retirement employment decisions. 
Third, the longitudinal data were collected with a lag of twelve years. Within this large time interval, there might have been changes in aging experience and post-retirement work status, which could not be captured by the current study. A collection of longitudinal data with a shorter time interval can provide additional information regarding the dynamics of the behavior to engage in post-retirement employment.

Fourth, large population surveys tend to face a bandwidth-measurement quality dilemma. By trying to accommodate a broad array of constructs of interests (wide bandwidth), the level of measurement quality in assessing those constructs may suffer. The four aging experience dimensions were measured with a four-item short scale each. Consequently, one dimension (i.e., gaining self-knowledge) had relatively lower reliability. Though the analysis methods used controlled for the downward-bias of unreliability on construct relationships, unreliable measurement still reduces the precision with which relationships can be estimated. Future research should focus on the measurement quality of aging experience by developing new items and improving scale reliabilities.

Fifth, in the current study, post-retirement employment was investigated as a dichotomous variable. However, as pointed out by previous researchers (e.g., Davis, 2003; Wang et al., 2008), post-retirement employment may include different types of employment (in the same career field vs. a different field) as well as different work hour schemes (parttime vs. full-time). The current study was not able to incorporate such fine-grained investigation on post-retirement employment types because either no relevant information was available in the data set or the resulted size of the subgroups was too small. As such, future research is needed to explore differentiated effects of aging experience regarding various types and work hour schemes of post-retirement employment. 
Sixth, the results are limited in generalizability because the data were based on a German sample only. Further research should take place in different cultural settings in order to sort out the potential effects of retirement and pension policy.

Different theoretical approaches may be able to explain the relationship between psychological aging experience and post-retirement employment. For example, although contradictory to our current finding, retirees who experience aging as gaining self-knowledge may be more likely to engage in post-retirement employment because they are more knowledgeable about their strengths. Future research should explore the underlying mechanisms through which different antecedents influence post-retirement employment. Wöhrmann et al. (2013) have pointed out that outcome expectations are highly relevant for post-retirement planning activities. These outcome expectations might be very helpful in further conceptualizing and operationalizing the approach and avoidance mechanisms we theorized in the current paper to link aging experience to post-retirement employment. Additionally, self-efficacy is likely to influence these relationships examined in the current study (Dittmann-Kohli et al., 1997; Wöhrmann et al., 2013). Therefore, future investigations on potential moderators and mediators may be helpful in order to explain the current findings relationship in more detail.

\section{References}

Aquino, J. A., Russell, D. W., Cutrona, C. E., \& Altmaier, E. M. (1996). Employment status, social support, and life satisfaction among the elderly. Journal of Counseling Psychology, 43, 480-489.

Atchley, R. C. (1982). The aging self. Psychotherapy: Theory, Research and Practice, 19, $388-396$.

Bandura A. (1986). Social foundations of thought and action: A social cognitive theory. Englewood Cliffs, NJ: Prentice-Hall. 
Beehr, T. a., Glazer, S., Nielson, N. L., \& Farmer, S. J. (2000). Work and nonwork predictors of employees' retirement ages. Journal of Vocational Behavior, 57, 206-225. doi:10.1006/jvbe.1999.1736

Cahill, K. E., Giandrea, M. D., \& Quinn, J. F. (2007). Down shifting: The role of bridge jobs after career employment. Aging and Work, 6, 1-11.

Christensen, K., Doblhammer, G., Rau, R., \& Vaupel, J. W. (2009). Aging populations: The challenges ahead. Lancet, 374, 1196-1208. doi:10.1016/S0140-6736(09)61460-4

Connidis, I. (1989). The subjective experience of aging: Correlates of divergent views. Canadian Journal on Aging, 8, 7-18. doi:10.1017/S0714980800011168

Dalen, H. P. Van, Henkens, K., Henderikse, W., \& Schippers, J. (2010). Do European employers support later retirement? International Journal of Manpower, 31, 360-373. doi:10.1108/01437721011050620

Davis, M. A. (2003). Factors related to bridge employment participation among private sector early retirees. Journal of Vocational Behavior, 63, 55-71. doi:10.1016/S00018791(02)00016-7

De Gracia Blanco, M., Garre Olmo, J., Arbonès, M. M., \& Monreal Bosch, P. (2004). Analysis of self-concept in older adults in different contexts. European Journal of Psychological Assessment, 20, 262-274. doi:10.1027/1015-5759.20.4.262

Deller, J., Liedtke, P. M., \& Maxin, L. (2009). Old-age security and silver workers: An empirical survey identifies challenges for companies, insurers and society. Geneva Papers on Risk and Insurance - Issues and Practice, 34, 137-157. doi:10.1057/gpp.2008.44

Deller, J., \& Pundt, L. (in press). Flexible transitions from work to retirement in Germany. In C.M. Alcover, G. Topa, M. Depolo, \& F. Fraccaroli (Eds.), Bridge employment: A research handbook. London: Routledge. 
Deutsche Rentenversicherung Bund [German Statutory Pension Insurance Scheme] (2013). Die richtige Altersrente für Sie [The right pension for you]. Berlin, Germany: Deutsche Rentenversicherung Bund.

Dittmann-Kohli, F. (1995). Das persönliche Sinnsystem. [The personal meaning system]. Göttingen, Germany: Hogrefe-Verlag.

Dittmann-Kohli, F., Kohli, M., Künemund, H., Motel, A., Steinleitner, C., \& Westerhof, G., with the infas Sozialforschung (1997). Lebenszusammenhänge, Selbst- und Lebenskonzeptionen [Life coherence, self-concept and life design: the conceptualization of the German Aging Survey]. Berlin, Germany: Freie Universität.

Elliot, A. J., \& Thrash, T. M. (2002). Approach-avoidance motivation in personality: Approach and avoidance temperaments and goals. Journal of Personality and Social Psychology, 82, 804-818. doi:10.1037//0022-3514.82.5.804

Engstler, H., \& Motel-Klingebiel, A. (2010). Datengrundlagen und Methoden des Deutschen Alterssurveys [Data base and methods of the German Aging Survey]. In A. MotelKlingebiel, S. Wurm, \& C. Tesch-Römer (Eds.), Altern im Wandel. Befunde des Deutschen Alterssurveys (pp. 34-60). Stuttgart, Germany: Kohlhammer.

Eurofound (2012). Income from work after retirement in the EU. Luxembourg: Publications Office of the European Union.

Griffin, B., \& Hesketh, B. (2008). Post-retirement work: The individual determinants of paid and volunteer work. Journal of Occupational and Organizational Psychology, 81, 101-121. doi:10.1348/096317907X202518

Heckhausen, J., Dixon, R. A., \& Baltes, P. B. (1989). Gains and losses in development throughout adulthood as perceived by different adult age groups. Developmental Psychology, 25, 109-121 
Herzog, A. R., House, J. S., \& Morgan, J. N. (1991). Relation of work and retirement to health and well-being in older age. Psychology and Aging, 6(2), 202-211.

Keller, M. L., Leventhal, E. A, \& Larson, B. S. (1989). Aging: The lived experience. International Journal of Aging and Human Development, 29, 67-82.

Kim, N., \& Hall, D. T. (2013). Protean career model and retirement. In M. Wang (Ed.), The Oxford Handbook of Retirement (pp. 102-116). New York: Oxford Univ. Press.

Kim, S., \& Feldman, D. C. (2000). Working in retirement: The antecedents of bridge employment and its consequences for quality of life in retirement. Academy of Management Journal, 43, 1195-1210. doi:10.2307/1556345

Lerner, R. M., \& Busch-Rossnagel, N. A. (Eds.) (1981). Individuals as producers of their own development: A life-span perspective. New York, NY: Academic Press.

Lim, V. K. G., \& Feldman, D. (2003). The impact of time structure and time usage on willingness to retire and accept bridge employment. International Journal of Human Resource Management, 14, 1178-1191.

Mariappanadar, S. (2013). Do retirement anxieties determine bridge employment preference? A study among pre-retirees in the Australian construction industry. Personnel Review, 42, 176-204. doi:10.1108/00483481311309375

Markus, H. R., \& Herzog, A. R. (1992). The role of the self-concept in aging. In K. W. Schaie \& M. P. Lawton (Eds.), Annual review of gerontology and geriatrics: Vol. 11, (pp. 110-143). New York: Springer.

Müller, A., De Lange, A., Weigl, M., Oxfart, C., \& Van der Heijden, B. (2013). Compensating losses in bridge employment? Examining relations between compensation strategies, health problems, and intention to remain at work. Journal of Vocational Behavior, 83, 68-77. doi:10.1016/j.jvb.2013.03.002 
Muthén, L. K., \& Muthén, B. O. (2012). Mplus user's guide (7th ed.). Los Angeles, CA: Muthén \& Muthén.

Neller, K. (2005). Kooperation und Verweigerung: Eine Non-response-Studie [Cooperation and refusal: A non-response study]. ZUMA-Nachrichten, 57, 9-36.

Organization for Economic Cooperation and Development [OECD] (2011). Health at a Glance 2011: OECD Indicators, OECD Publishing. doi: 10.1787/health_glance-2011en.

Organization for Economic Cooperation and Development [OECD] (2013). StatExtracts. Dataset: Labour force statistics - sex and age indicators. Retrieved from http://stats.oecd.org/Index.aspx?DatasetCode=LFS_SEXAGE_I_R

Schöllgen, I., Huxhold, O., \& Schmiedek, F. (2012). Emotions and physical health in the second half of life: Interindividual differences in age-related trajectories and dynamic associations according to socioeconomic status. Psychology and Aging, 27(2), 338352. doi:10.1037/a0026115

Shultz, K. S. (2003). Bridge employment: Work after retirement. In G. A. Adams \& T. A. Beehr (Eds.), Retirement: Reasons, processes, and results, (pp. 215-241). New York, NY: Springer.

Shultz, K. S., \& Wang, M. (2011). Psychological perspectives on the changing nature of retirement. American Psychologist, 66, 170-9. doi:10.1037/a0022411

Steverink, N., Westerhof, G. J, Bode, C., \& Dittmann-Kohli, F. (2001). The personal experience of aging, andividual resources, and subjective well-being. Journal of Gerontology: Psychological Sciences, 56B(6), 364-373.

Wang, M. (2007). Profiling retirees in the retirement transition and adjustment process: Examining the longitudinal change patterns of retirees' psychological well-being. Journal of Applied Psychology, 92, 455-74. doi:10.1037/0021-9010.92.2.455 
Wang, M., Adams, G. A., Beehr, T. A., \& Shultz, K. S. (2009). Career issues at the end of one's career: Bridge employment and retirement. In S. G. Baugh \& S. E. Sullivan (Eds.), Maintaining focus, energy, and options through the life span: 135-162. Charlotte, NC: Information Age.

Wang, M., \& Shi, J. (2014). Psychological research on retirement. Annual Review of Psychology, 65, 209-233.

Wang, M., \& Shultz, K. (2010). Employee retirement: A review and recommendations for future investigation. Journal of Management, 36, 172-206.

Wang, M., Zhan, Y., Liu, S., \& Shultz, K. (2008). Antecedents of bridge employment: A longitudinal investigation. Journal of Applied Psychology, 93, 818-830.

Warr, P., Butcher, V., Robertson, I., \& Callinan, M. (2004). Older people's well-being as a function of employment, retirement, environmental characteristics and role preference. British Journal of Psychology, 95, 297-324.

Weckerle, J. R., \& Shultz, K. S. (1999). Influences on the bridge employment decision among older U.S. workers. Journal of Occupational and Organizational Psychology, $72,317-330$.

Wöhrmann, A. M., Deller, J., \& Wang, M. (2013). Outcome expectations and work design characteristics in post-retirement work planning. Journal of Vocational Behavior, 83, 219-228. doi:10.1016/j.jvb.2013.05.003

Wurm, S., Tesch-Römer, C., \& Tomasik, M. J. (2007). Longitudinal findings on agingrelated cognitions, control beliefs, and health in later life. Journal of Gerontology: Psychological Sciences, 62B(3), 156-164.

Zhan, Y., Wang, M., Liu, S., \& Shultz, K. (2009). Bridge employment and retirees' health: A longitudinal investigation. Journal of Occupational Health Psychology, 14(4), 374 389. doi:10.1037/a0015285 
Table 1: Means, standard deviations and correlations for study variables $(N=488-551)$

\begin{tabular}{|c|c|c|c|c|c|c|c|c|c|c|c|c|c|}
\hline Variable & $\mathrm{M}$ & $\mathrm{SD}$ & 1 & 2 & 3 & 4 & 5 & 6 & 7 & 8 & 9 & 10 & 11 \\
\hline \multicolumn{14}{|l|}{ Control variables } \\
\hline 1. Age & 71.92 & 6.30 & - & & & & & & & & & & \\
\hline 2. Gender $(0=$ female, $1=$ male $)$ & 0.56 & 0.50 & -.03 & - & & & & & & & & & \\
\hline 3. Education & 2.24 & 0.62 & $-.12 * *$ & $.28 * *$ & - & & & & & & & & \\
\hline 4. Subjective health & 3.41 & 0.81 & $-.20 * *$ & -.03 & $.09 *$ & - & & & & & & & \\
\hline 5. Subjective economic status & 3.76 & 0.68 & .03 & .04 & $.13 * *$ & $.24 * *$ & - & & & & & & \\
\hline 6. Employment status $\mathrm{T}_{1}$ & 0.47 & 0.50 & $-.58 * *$ & $.15^{* *}$ & $.21 * *$ & $.21 * *$ & .04 & - & & & & & \\
\hline \multicolumn{14}{|l|}{ Predictor variables } \\
\hline 7. Physical loss & 2.85 & 0.58 & .07 & -.04 & -.06 & $-.22 * *$ & $-.16 * *$ & -.07 & - & & & & \\
\hline 8. Social loss & 1.71 & 0.60 & .02 & -.04 & .03 & -.04 & $-.15 * *$ & -.07 & $.28 * *$ & - & & & \\
\hline 9. Personal growth & 2.95 & 0.57 & $-.12 * *$ & -.05 & .05 & $.11 * *$ & $.13 * *$ & $.11 *$ & $-.27 * *$ & $-.31 * *$ & - & & \\
\hline 10. Gaining self-knowledge & 3.08 & 0.53 & .01 & -.06 & -.03 & -.06 & .03 & -.03 & .08 & -.06 & $.39 * *$ & - & \\
\hline \multicolumn{14}{|l|}{ Dependent variable } \\
\hline 11. Post-retirement employment & 0.08 & 0.28 & $-.19 * *$ & .06 & .06 & $.15 * *$ & $.07 *$ & $.24 * *$ & $-.12 * *$ & -.01 & $.08^{*}$ & -.05 & - \\
\hline
\end{tabular}
$* p<.05$. ** $p<.01$. 
Table 2: Comparison between the different models $(N=545)$

\begin{tabular}{rccc}
\hline \multicolumn{1}{l}{ Model fit } & Model 1 & Model 2 & Model 3 \\
\hline Log likelihood & -8155.07 & -8132.53 & -8128.19 \\
$-2 \log$ likelihood & 16310.13 & 16265.06 & 16256.37 \\
$\Delta \mathrm{df}$ & & 6 & 4 \\
$\Delta-2 \log$ likelihood & & $45.07^{* *}$ & $8.69^{\dagger}$ \\
Cox and Snell pseudo R ${ }^{2}$ & & 0.08 & 0.09 \\
\hline
\end{tabular}

Note. Model 1 = null model. Model 2 = model including only effects of control variables. Model $3=$ model including effects of both control variables and hypothesized predictors. $\dagger p<.10 . * p<.05 . * * p<.01$. 




Fig. 1. Longitudinal structural equation model for psychological aging experiences related to post-retirement employment, including control variables (age, gender, education, subjective health, subjective economic status, and post-/pre-retirement employment at $\mathrm{T}_{1}$ ). $\mathrm{T}_{1}=$ Time 1 and $\mathrm{T}_{2}=$ Time 2 . Unstandardized estimates and hypothesis $(\mathrm{H})$ are shown.

$\dagger \mathrm{p}<.10$.

$* \mathrm{p} \leq .05$.

$* * \mathrm{p}<.01$. 